\title{
Screening Diabetic Retinopathy by smartphone, which adapter to choose? Algerian model (Youssouf Dr Model)
}

\author{
Belazzouz Abderrahmen Youssouf* \\ Internal Medicine Department, Sisters Bedj Hospital, Algeria
}

Submission: October 09, 2019; Published: November 13, 2019

*Corresponding author: Belazzouz Abderrahmen Youssouf, Internal Medicine Department, Sisters Bedj Hospital, City 42 log N37 Chettia Chlef, Algeria

\begin{abstract}
Diabetes mellitus has become a global epidemic, this increase in frequency is the result of screening more and more frequent. The improvement in therapeutic management has made that survival among diabetics has increased enormously and has made a transition of complications forms ranging from fatal renal complications to complications threatening the functional prognosis (like diabetic retinopathy). The latter is often discovered at a late stage because of several causes, some of which are related to the pathology (silent, rarely florid), others related to the patient (inobservance of the monitoring of complications checkup) and the environment (social conditions). The current time with the new therapies against diabetes must make diabetologists involved in a process of screening for this silent pathology and conducted scientific studies to establish new therapeutics safety on eyes. To facilitate this screening policy, we have to put at their disposal tools like smartphone, lens and adapter whose choice must not only take into account its practical nature but also solid and cheap. If everyone agrees to offer Volk as the most preferred lens and IPhone as smartphone of choice, it is not yet the case to adapter. I proposed an Algerian model based on what is available as an asset in everyday life which costs 10 times less than American adapter, that's why it is advised that each developing country offers its own adapter depending on the local material because of difference between the currency of developing and developed countries.
\end{abstract}

Keywords: Diabetic retinopathy; Screening; Adapter; Diabetes; Diabetologists; New therapeutics; Eyes; Glaucoma; Cataract; Ophthalmologists; Pupillary dilation

\section{Introduction}

Nowadays, we see more and more diabetics all over the world; we find that they are screened rarely by ophthalmologists. This may be related to several factors that depend on the asymptomatic character of the pathology in its early form and other factors related to the patient whether for financial reasons especially in developing countries or because of the lazy nature of some patients. Especially in front of the loaded consultations of the ophthalmologists who are surpassed by the surgical part of their specialty and the other pathologies (such as: glaucoma and cataract). As a result, Diabetic retinopathy, which is the leading cause of blindness in adulthood, is often diagnosed at a late or complicated form, which exacerbates the costs of its therapeutic management. All this embody the saying: prevent is better than cure.

For the above-cited reasons, and in order to involve diabetologists in screening campaigns, it was necessary to master a simple, inexpensive and practical tool at their disposal. The material we need consists of smartphone [1], lens and adapter and it is the latter that we will discuss in detail in this manuscript by recalling the different forms existing in the market (advantages and disadvantages) and proposing an Algerian model in comparison with American and especially Indian models [2].

The examination procedure is preferably to sit comfortably for the patient and the doctor, in a low-light room, a small pupillary dilation of $5 \mathrm{~mm}$ is sufficient. However, some retinal photography does not require dilation (IPhone) [1]. The examination lasts between 3 to 5 minutes according to the physician experience and patient compliance. The smartphone uses a light beside camera. Adapter consists of 2 devices one fixing lens and the other fixing the smartphone connected by an arm of a length about 15 to 20 centimeters (Figures $1 \& 2$ ). 


\section{Current Research in Diabetes \& Obesity Journal}

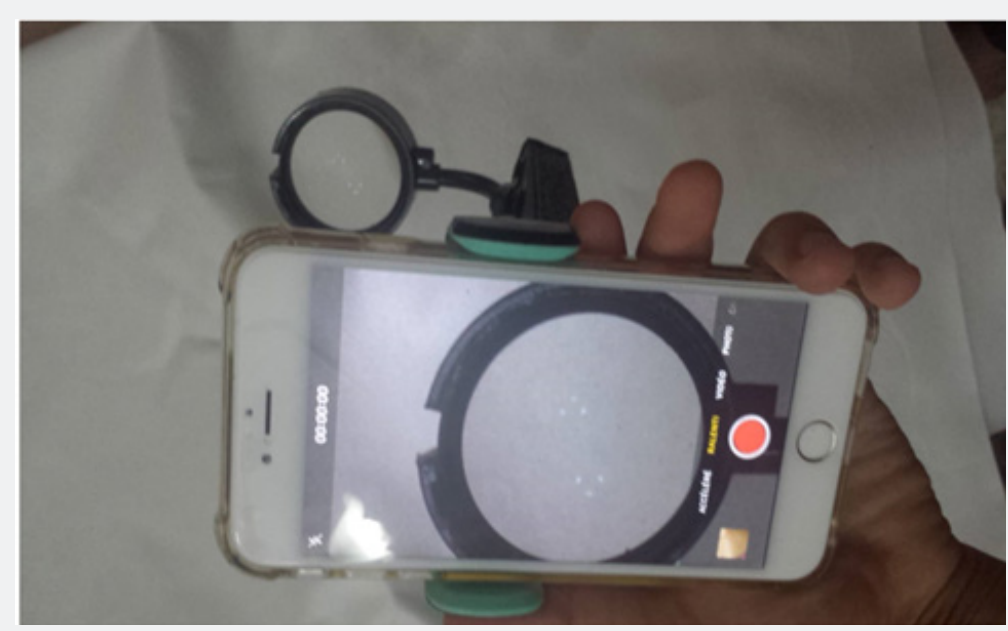

Figure 1: Front View of Youssouf Dr Adapter with Smartphone and Lens in Place.

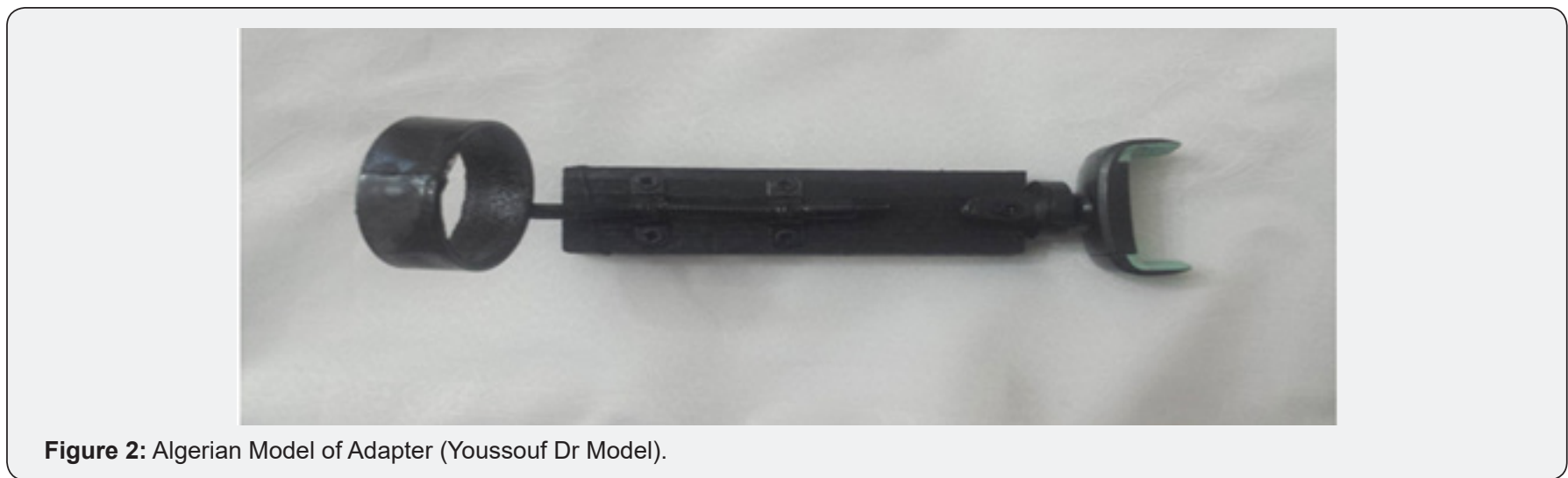

I used the smartphone's handheld in the car in order to fix smartphone and the web camera of the laptop computer in order to fix lens, then I connected the two on a wooden board in the thickness is suitable for 2 devices (with plastic, it is difficult to fix on the other two parts because quickly breakable) (Figures 3 \& 4). The images can be interpreted in deferred time, which opens track to the artificial intelligence and telemedicine.

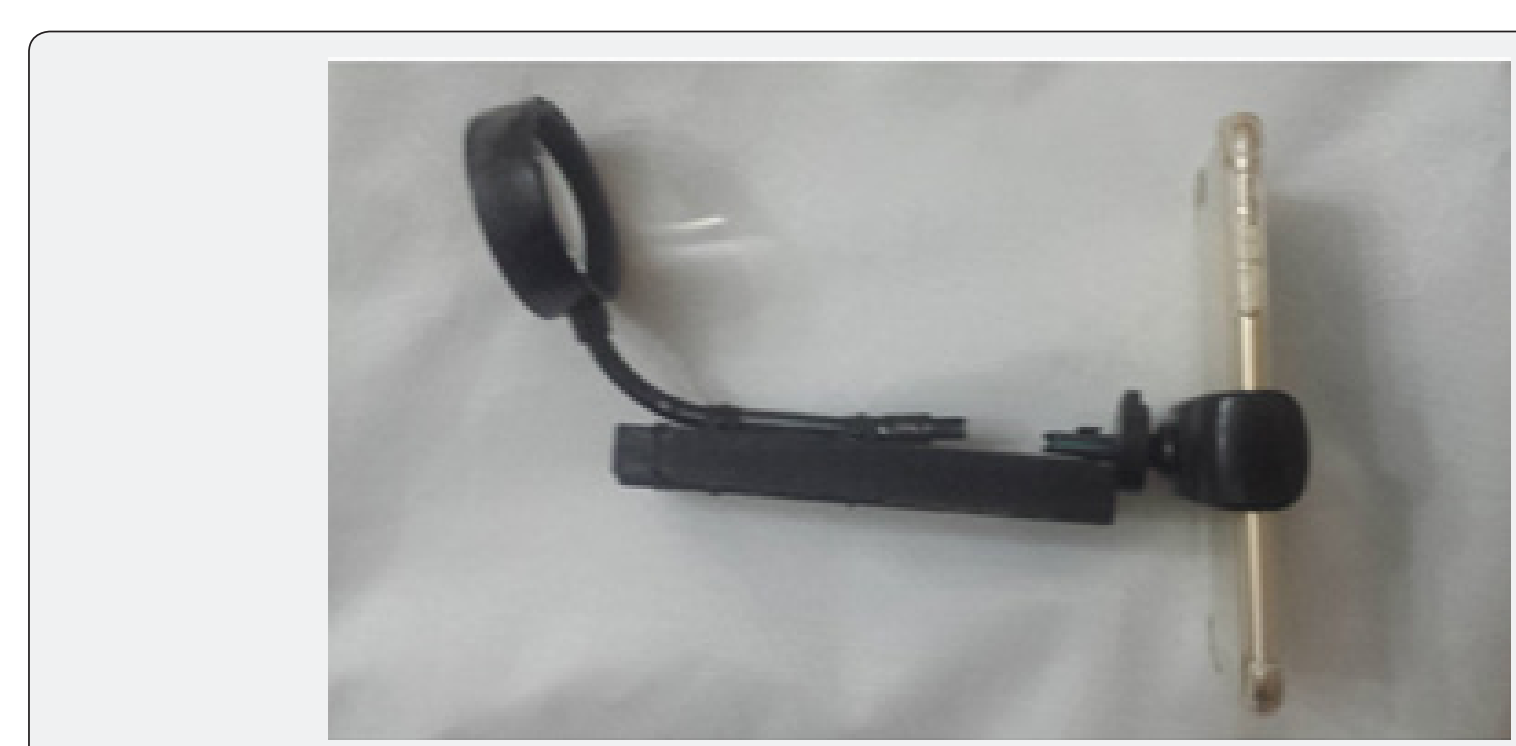

Figure 3: Profile View of Algerian Model Adapter. 


\section{Current Research in Diabetes \& Obesity Journal}

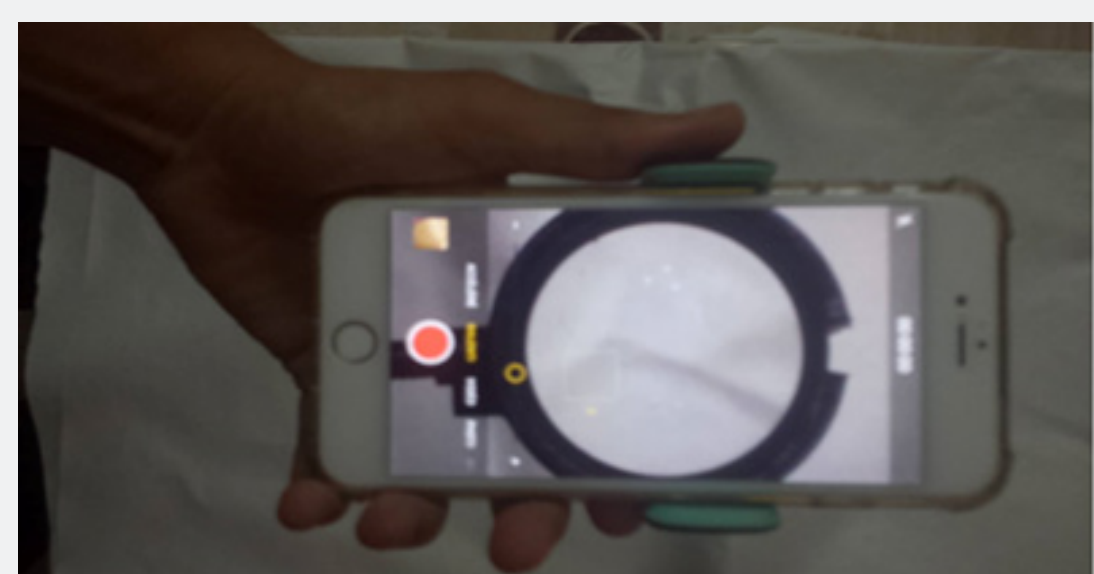

Figure 4: Image Quality with Lens in the Center of the Smartphone Camera Field.

Americans have proposed a solid and open air adapter but too much expensive for doctors overall the world (Figure 5). Indians have proposed several models of adapters some of which are economic without being solid (Figure 6). From all this come the idea of proposing an Algerian model. This adapter costs 1500 Algerian dinars, which is 10 times less compared to the price of an American adapter.

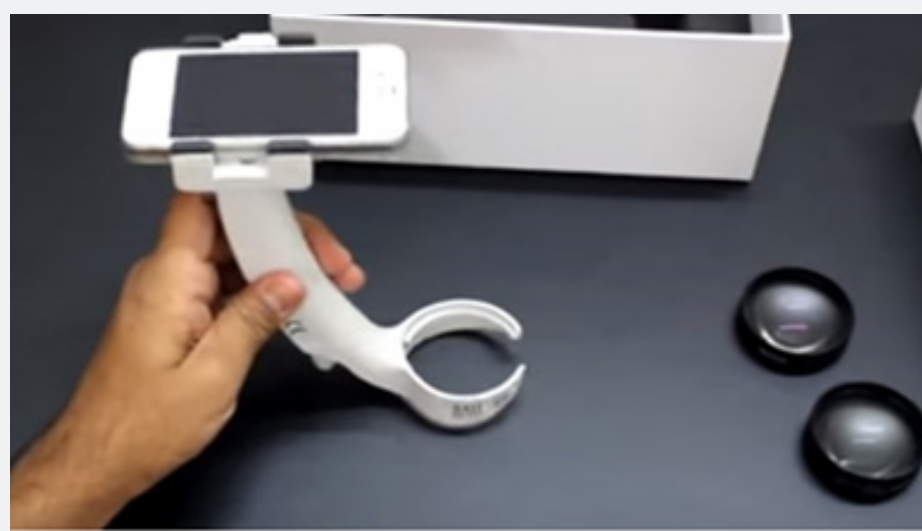

Figure 5: M II RET Cam Adapter Model.

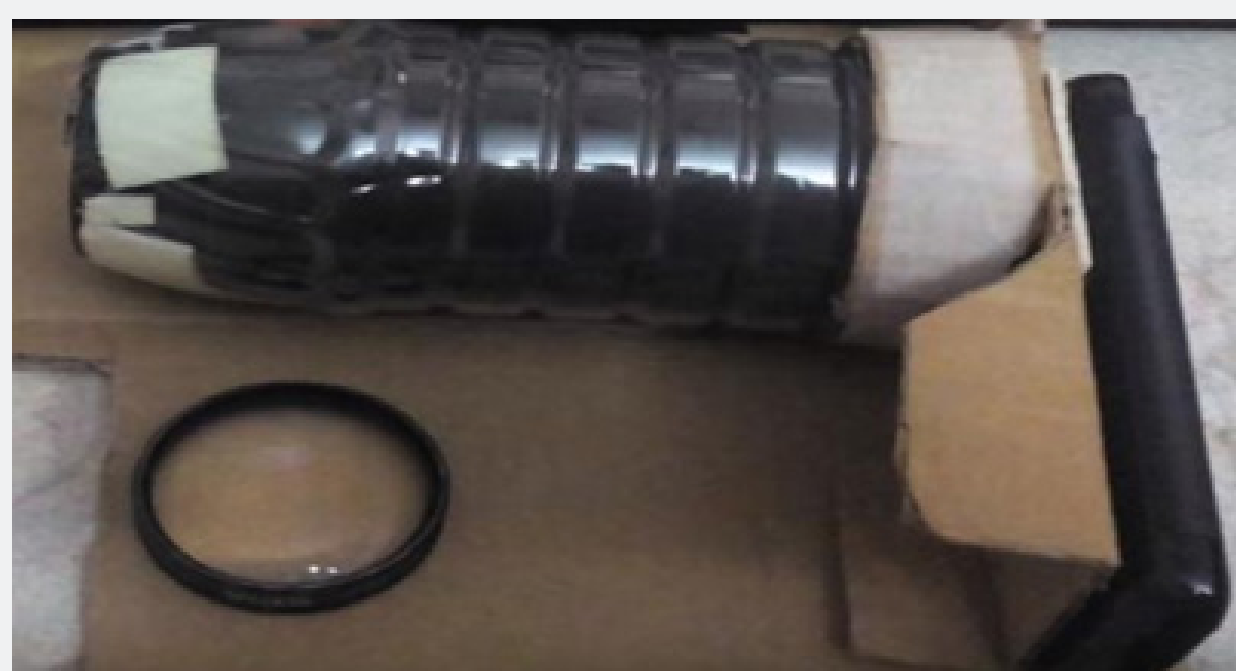

Figure 6: Indian Adapter Model. 
Knowing that patients suffering from ocular symptoms such as pain, redness of the eye should be entrusted to an ophthalmologist, as well as patients suffering from cataracts or refractory vice requiring correction by glasses. The interest of involving diabetologists in these screening campaigns is above all the benefit of diabetic patients to improve their overall care. But also makes it possible to conduct scientific studies on this aspect if we know that until today no major interventional study has interested the impact of different new therapeutics on the eyes. Also, the fact of being able to prove effect of some natural molecules on diabetic retinopathy reversibility and its improvement.

\section{Conclusion}

The diabetologist by becoming involved in the screening is free to choose smartphone adapter that suits him, nevertheless a cheap device adapted to the daily practice is desirable. The progress of recent years in this area aims to detect the maximum of diabetic patients, which will allow in the short term to reduce the costs of consultations and in the long term reduce the financial burden to spend by the state in taking in charge of complicated forms discovered late. This health policy concretizes saying prevent is better than cure.

\section{References}

1. Chhablani J, Kaja S, Shah VA (2012) Smartphones in ophthalmology. Indian J Ophthalmol 60(2): 127-131.

2. Ludwig CA, Murthy SI, Pappuru RR, Jais A, Myung DJ, et al. (2016) A novel smartphone ophthalmic imaging adapter: User feasibility studies in Hyderabad, India. Indian J Ophthalmol 64(3): 191-200.

3. Lamirel C, Bruce BB, Wright DW, Newman NJ, Biousse V (2012) Nonmydriatic digital ocular fundus photography on the iPhone 3G: The FOTO-ED study. Arch Ophthalmol 130(7): 939-940.

\begin{tabular}{l} 
Your next submission with Juniper Publishers \\
will reach you the below assets \\
- Quality Editorial service \\
- Swift Peer Review \\
- Reprints availability \\
- E-prints Service \\
- Manuscript Podcast for convenient understanding \\
- Global attainment for your research \\
- Manuscript accessibility in different formats \\
( Pdf, E-pub, Full Text, Audio) \\
- Unceasing customer service \\
Track the below URL for one-step submission \\
https://juniperpublishers.com/online-submission.php \\
\hline
\end{tabular}

